\title{
Spatial modeling of long-term air temperatures for sustainability: Evolutionary fuzzy approach and neuro-fuzzy methods
}

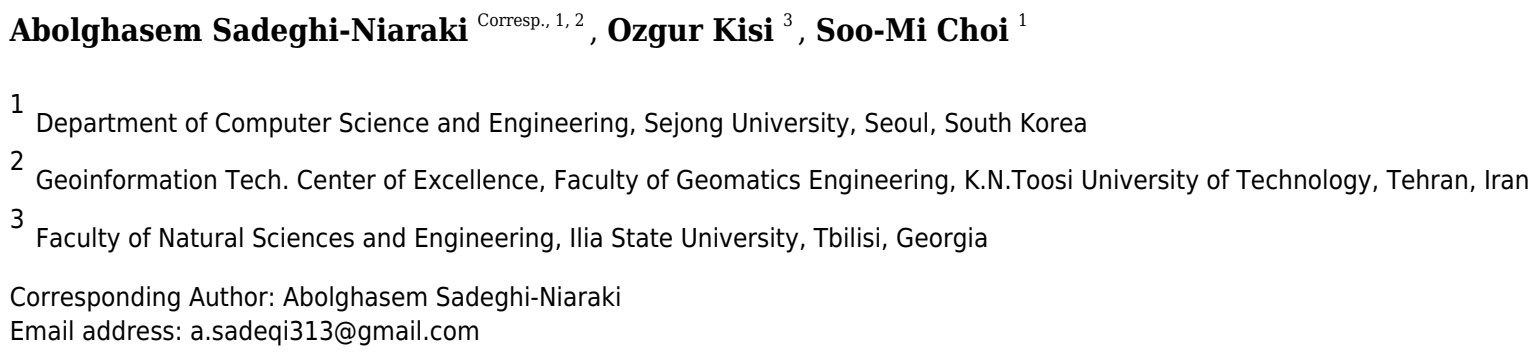

This paper investigates the capabilities of the evolutionary fuzzy genetic (FG) approach and compares it with three neuro-fuzzy methods-neuro-fuzzy with grid partitioning (ANFIS-GP), neuro-fuzzy with subtractive clustering (ANFIS-SC), and neuro-fuzzy with fuzzy c-means clustering (ANFIS-FCM) -in terms of modeling long-term air temperatures for sustainability based on geographical information. In this regard, to estimate long-term air temperatures for a 40-year (1970-2011) period, the models were developed using data for the month of the year, latitude, longitude, and altitude obtained from 71 stations in Turkey. The models were evaluated with respect to mean absolute error (MAE), root mean square error (RMSE), Nash-Sutcliffe efficiency (NSE), and the determination coefficient (R2). All data were divided into three parts and every model was tested on each. The FG approach outperformed the other models, enhancing the MAE, RMSE, NSE, and R2 of the ANFIS-GP model, which yielded the highest accuracy among the neuro-fuzzy models by $20 \%, 30 \%$, and $4 \%$, respectively. A geographical information system was used to obtain temperature maps using estimates of the optimal models, and the results of the model were assessed using it. 
2 Spatial modeling of long-term air temperatures for 3 sustainability: Evolutionary fuzzy approach and neuro-fuzzy 4 methods

Keywords: Long-term air temperature; estimation, evolutionary fuzzy; neuro-fuzzy; GIS. 


\section{Introduction}

Regional climate is critical to the efficiency of crops as it deeply influences their yield potential. Rainfall, solar irradiance, and the temperature of the air are factors affecting crop yield, improvement, and growth (Ali-Nezhad and Eskandari, 2012). With regard to the phonological levels of the ripening of a crop, temperature is considered vital. (Rosenzweig and Liverman, 1992). Moreover, crop growth is done within only specific temperature ranges. While the growth of a plant relies heavily on temperature, the plant species is the most significant determinant of the range of temperature ideal for its growth (Hasanuzzaman et al., 2013). Temperature determines the crop's survival and growth in each region (Cobaner et al. 2014). Brunetti et al. (2014) discuss the pros and cons of 3 spatial models such as multi-linear regression with local improvements (MLRLI), regression kriging (RK), local weighted linear regression (LWLR) considering elevation input for temperature assessment in Italy. Hidalgo et al. (2015) employ spatial trend analysis based on the interpolation method such as radial weight with a Gaussian shape using angular weight for temperature data analysis. Serrano-Notivoli et al. (2019) evaluate spatial, temporal variability of temperature using methods such as Generalized Linear Mixed (GLMM) and Generalized Linear Models (GLM) with the inclusion of spatial predictors such as latitude, longitude, altitude, and distance.

Techniques from artificial intelligence (AI), such as the adaptive neuro-fuzzy inference system (ANFIS) and artificial neural networks (ANN), have been used in such subjects as agro-hydrology, agro-meteorology, and engineering for water resources. This study focuses on the relevant literature. Zhu et al. (2019) proposed a model using different machine learning techniques such as multilayer perceptron neural network models (MLPNN), adaptive neuro-fuzzy inference systems (ANFIS) with fuzzy c-mean clustering algorithm (ANFIS_FC), ANFIS with grid partition method (ANFIS_GP), and ANFIS with subtractive clustering method (ANFIS_SC) for prediction of water temperature. Khosravi et al. (2018) employs a model using multilayer feed-forward neural network (MLFFNN), radial basis function neural network (RBFNN), support vector regression (SVR), fuzzy inference system (FIS) and adaptive neuro-fuzzy inference system (ANFIS) for solar radiation prediction.

The abductive neural network method was utilized by Abdel-Aal to predict air temperature every hour. Using data concerning seasonality and changing the parameters of an ANN model, Smith et al. (2005) developed an ANN for temperature forecasting. Dew-point temperature was modeled 
by Shank et al. (2008) using neural networks, and Turkey's long-term temperature forecasting was applied by Bilgili and Sahin (2009) to each month. A new method utilizing the Yule-Walker equation and ANNs was proposed by Chattopadhyay et al. (2011) to model the time series of monthly maximum temperatures in northeast India. Turkey's mean air temperature for each month was modeled by Sahin (2012) using ANN and remote sensing. By using geographical data, the performance of ANNs and ANFIS was compared in terms of forecasting air temperature in Iran by Kisi and Shiri. In another study, the monthly mean of Turkey's air temperature was predicted by Cobaner et al. (2014) using ANNs and ANFIS. All past assessments have used ANFIS and ANNs, and none of them has evaluated fuzzy methods for long-term modeling of temperature by applying geographical information. Thus, this paper aims to model long-term temperatures using geographical data and compare an evolutionary fuzzy method with three approaches based on ANFIS.

Some researchers in climatology, biogeography, hydrology, meteorological, agriculture, and ecology have applied temperature modeling using spatial/geographical information systems (GIS) (Ninyerola et al., 2000). Goodale et al. (1998) applied predictors to interpolate temperature and precipitation in Ireland using spatial information (latitude, longitude, and altitude). Geostatistical model kriging was employed by Benavides et al. (2007) to model temperature. Chuanyan et al. (2005) compared the results of conventional predictive models, such as linear regression and geostatistical interpolation techniques (e.g., ordinary kriging, splines, and inverse distance weight), in terms of spatial distribution in modeling surface air temperature. Ninyerola et al. (2000) also employed GIS-based techniques for the accurate prediction and mapping of the nonlinear behavior of air temperature over space and time.

To predict long-term monthly air temperature with spatial data for achieving sustainability, in this research the evolutionary fuzzy genetic (FG) model applicability is examined. The results of the proposed model were evaluated by comparing with those of three ANFIS models: ANFIS using fuzzy c-means clustering (ANFIS-FCM), ANFIS using grid partitioning (ANFIS-GP), and ANFIS using subtractive clustering (ANFIS-SC). In this regard, training and testing the FG and ANFIS models were conducted on 71 weather stations data in Turkey. The results were also evaluated using the GIS method. 


\section{Study area}

The $37^{\text {th }}$ largest country in the world, Turkey is located at $38.9637^{\circ} \mathrm{N}$ latitude and $35.2433^{\circ} \mathrm{E}$ longitude with an area of $780,000 \mathrm{~km}^{2}, 25$ million hectares of which is suited for agriculture. Turkey is a mountainous country with large plains. The highest mountain, Ararat, is 5165 meters high. The distribution of temperature and weather patterns are significantly influenced by the orientation and elevation of mountains in the country.

This study used monthly mean temperatures gathered from 71 stations of the Turkish State Meteorological Service. This information included a 40-year dataset from 1970-2011 for each station. Table 1 shows the temperature $\left({ }^{\circ} \mathrm{C}\right)$, longitude, latitude, and altitude above sea level as recorded by each station. The temperature varied from $-11.5^{\circ} \mathrm{C}$ in January (Ardahan) to $32{ }^{\circ} \mathrm{C}$ in July (Urfa) in the long term. The high variation may have occurred because of the sea rounding these areas, the high mountains along the coasts of the Black Sea and the Mediterranean Sea, and the mountainous eastern Anatolia region (Cobaner et al., 2014). Figure 1 shows the meteorological stations distribution in Turkey.

\section{Methods}

\subsection{Fuzzy approach}

Fuzzy logic has been used in such fields as business, engineering, and the sciences (Zadeh, 1965). Figure 2 shows units of fuzzification of a general fuzzy system including a fuzzy inference engine, a fuzzy rule base, and defuzzification. Fuzzy logic is based on the idea of using hybrid systems, where part of one system and part of another are used instead of only one. The degree of dependence on a system is a number between zero and one.

In the inference mode, the fuzzy system takes inputs and outputs data. By using a map of association, namely fuzzy associative memory, the inputs are transformed into the equivalent output sets by fuzzy system learning (Kosko, 1993). Some "black box" approaches such as ANNs can function, for example, in regression, but fuzzy systems are clearer and more pliable. Thus, it is clear how fuzzy systems perform and modify processes (Russel \& Campbell, 1996). 
The fuzzy method used here is as follows. Several subsets using Gaussian member function are formed from the input and output parameters. ck fuzzy rules are available, where $\mathrm{c}$ and $\mathrm{k}$ are the subsets and inputs numbers, respectively. Efficiency increases with the number of subsets, and the rule base increases in weight, rendering construction more complex. In the case of only one input, $x$, and $k$ subsets, the rule base yields yn $(n=1,2, \ldots, k 2)$ (Şen, 1998).

In the case of one variable input, $x$ with four values of "low," "medium," "high," and "very high," four rules are possible:

$\mathrm{R} 1$ : IF $\mathrm{x}$ is "low," THEN $\mathrm{y}_{1}$

R2: IF $\mathrm{x}$ is "medium," THEN $\mathrm{y}_{2}$

R3: IF $x$ is "high," THEN $y_{3}$

R4: IF $\mathrm{x}$ is "very high," THEN $\mathrm{y}_{4}$

The output is single weighted, $y$, as a weighted average of the outputs of these four rules as follows:

$y=\frac{\sum_{n=1}^{4} w_{n} \cdot y_{n}}{\sum_{n=1}^{4} w_{n}}$

where the degree of membership, $\mathrm{w}_{\mathrm{n}}$, is investigated for each $\mathrm{x}$ to be assigned an equivalent $\mathrm{y}_{\mathrm{n}}$ after triggering each rule.

Therefore, having formed the rule base, any assortments of subsets of the parameters used as input to the fuzzy system, Eq. (1), can be used to compute the output values (y) (Şen, 1998).

The proposed fuzzy base rule can be computed using the datasets used as input and output as follows:

1. using the smallest number of inputs;

2. assigning a specific membership function to each input;

3. computing the value of membership $\left(\mathrm{w}_{\mathrm{n}}\right)$ of $\mathrm{x}$ in all fuzzy subsets;

4. calculating the output $\mathrm{y}_{\mathrm{n}}$ simultaneously with the weight set $\mathrm{w}_{\mathrm{n}}$;

5. renewing all other data points; and

6. calculating the weighted average using Eq. (1) (Kiszka et al., 1985a; Kiszka et al., 1985b). As any change in the subsets makes a direct effect on the functionality of the fuzzy model, forming the fuzzy subsets is among the most challenging problems in the area. It is thus vital to define the membership functions optimally to maximize modeling efficiency (Kisi and Cengiz, 2013). The optimal membership functions are defined in this research using the genetic algorithm. 


\section{$149 \quad 3.2$ Genetic algorithm}

150 GAs have been researched in engineering since 1960, when they were introduced by Holland 151 (Abraham et al., 2005; Ortiz et al., 2004). In general, GAs try to imitate the Darwinian concept of 152 natural selection. A GA first generates a set of possible solutions and tries to find the best approach

153 154 155 to survival to form a new population of solutions, which assesses the real solution better than before. The challenge of creating better and fitter solution sets is the basic principle of GAs. They are utilized to find the best and most optimal solutions to solve difficult problems. Utilizing this approach provides a useful option for solutions (Aijun et al., 2004; Tsai et al., 2004). While other methods are restricted due to their suppositions, GAs have fewer such limits (Jean et al., 2007).

\subsection{Adaptive neuro-fuzzy inference system}

ANFIS, a general investigation tool with the quality to approximate continuous real functions on compact sets, was developed in 1993 by Jang. In its structure, nodes are attached to one another by directional links. A node function containing variable or constant parameters introduces the node (Jang et al., 1997).

The example below presents a typical fuzzy inference system (FIS) with an output $f$, three inputs $\mathrm{x}, \mathrm{y}$, and $\mathrm{z}$, and two if-then fuzzy rules of the Takagi and Sugeno type:

Rule 1: If $\mathrm{x}$ is $\mathrm{A} 1, \mathrm{y}$ is $\mathrm{B} 1$, and $\mathrm{z}$ is $\mathrm{C} 1$, then $f_{1}=p_{1} x+q_{1} y+r_{1} z+s_{1}$

$$
\text { Rule 2: If } \mathrm{x} \text { is } \mathrm{A} 2, \mathrm{y} \text { is } \mathrm{B} 2 \text {, and } \mathrm{z} \text { is } \mathrm{C} 2 \text {, then } f_{2}=p_{2} x+q_{2} y+r_{2} z+s_{2}
$$

where $f_{1}$ and $f_{2}$ are the output functions of rules 1 and 2 , respectively. Figure 3 shows the structure of ANFIS. The functions of the nodes are as follows.

$O_{l, i}=\varphi A_{i}(x)$ indicates the node function for each square node $\mathrm{i}$ of layer 1 that is adaptive, and $\mathrm{i}=$ $1,2, \mathrm{x}$, is the $\mathrm{i}^{\text {th }}$ input node; $\mathrm{A}_{\mathrm{i}}$ is a linguistic label (i.e., "small" or "big") for this node function. When input $\mathrm{x}$ satisfies quantifier $\mathrm{A}_{\mathrm{i}}, \mathrm{O}_{1, \mathrm{i}}$, is the membership function (MF) of fuzzy set A (e.g., $\left.\mathrm{A}_{1}, \mathrm{~A}_{2}, \mathrm{~B}_{1}, \mathrm{~B}_{2}, \mathrm{C}_{1}, \mathrm{C}_{2}\right)$ and indicates its degree. $\varphi A_{i}(x)$ is mainly a Gaussian function ranging between zero and one as the minimum and maximum levels, respectively:

$$
\varphi A_{i}(x)=\exp \left(-\left(\frac{x-a_{i}}{b_{i}}\right)^{2}\right)
$$


177

178

179

180

181

182

183

184

185

where $\left\{a_{i}, b_{i}\right\}$ is the parameter set. These layer parameters are considered to be assumed. The circle nodes of layer 2 have index $\Pi$, which indicates the multiplication of the inputs and the sending of the product. For instance, $w_{i}=\varphi A_{i}(x) \varphi B_{i}(y) \varphi C_{i}(z), \mathrm{i}=1,2$. The output of each node shows the impression level of a rule. Circle nodes of layer 3 take the label N. Following this, the ratio of the level of impression of the $i^{\text {th }}$ rule on the sum of the levels of all rules is computed by the $i^{\text {th }}$ node using

$$
\bar{w}_{i}=\frac{w_{i}}{w_{1}+w_{2}}, \quad \mathrm{i}=1,2 .
$$

The node function of the square nodes of layer 4 is $O_{4, i}=\bar{w}_{i} f_{i}=\bar{w}_{i}\left(p_{i} x+q_{i} y+r_{i} z+s_{i}\right)$, where $\bar{w}_{i}$ represents the layer 3 output and the parameter series is $\left\{p_{i}, q_{i}, r_{i}, s_{i}\right\}$. These layer parameters are called consequent parameters. The single circle nodes of layer 5, labeled " $\Sigma$," sums all incoming signals and returns the result as the final output:

$$
O_{5, i}=\sum_{i=1} \bar{w}_{i} f_{i}=\frac{\sum_{i} w_{i} f_{i}}{\sum_{i} w_{i}}
$$

The ANFIS network acts similarly to a first-order Sugeno FIS (Kisi, 2015). Linear or fixed-valued functions are used in ANFIS to generate the output. Detailed information concerning ANFIS is available in Jang's study (1993).

\subsection{Grid partitioning}

This approach provides independent partitions of prior variables (Jang, 1993). The membership functions of all prior variables can be determined by prior knowledge and experience. Expressing the meaning of the linguistic terms of a context is the goal of designing these partitions. However, in many systems, there is no specific information accessible to these partitions. Thus, the ranges of the prior variables may easily be divided into membership functions that are equally shaped and spaced. The membership functions may be located suitably in case the system's input-output data are available. The rule base should be generated in a manner that perfectly covers previous fuzzy set combinations. The membership functions of each variable are built apart from those of others, 
202 and this is the main disadvantage of this method as this causes it to overlook the relationship among

203 variables (Vernieuwe et al. ,2005).

\subsection{Subtractive clustering}

The ANFIS subtractive clustering (ANFIS-SC) model is defined by merging ANFIS with subtractive clustering. In this model, a possible cluster center is each data point, which is not a grid point (Chiu, 1994). It is thus an extended model of Yager and Filev (1994), the mountain clustering method.

In this approach, the number of effective "grid points" that should be investigated are similar to the number of data points independently of the number of dimensions of the problem. One of the advantages of this approach is that a tradeoff between computational complexity and accuracy is unnecessary because the need to define a grid resolution is removed. The scale of the mountain method to accept or reject the cluster centers is also extended in subtractive clustering.

The impressive radius is vital to defining the number of clusters. Too many smaller clusters require more rules if a small radius is chosen, and vice versa. Thus, selecting a suitable impressive radius for data space clustering is crucial. Defining the number of fuzzy rules and presumptions of the fuzzy MF is the next stage. In the end, the results in the output MF are generated by utilizing linear least squares, which builds a valid FIS (Cobaner, 2011; Sanikhani and Kisi, 2012).

\subsection{Fuzzy c-means clustering}

C-means fuzzy clustering is a form of flexible clustering model in which the data points are combined by calculating possible data points in the feature space. In this model, the mountain clustering approach can be used to calculate the number of clusters and cluster centers (Chiu, 1994; Cobaner, 2011). This model is based on the k-means algorithm, which is unsuitable for big datasets. C-means fuzzy clustering reduces the intra-cluster variance to a minimum (Ayvaz et al., 2007) and combines data using its clustering algorithm. The c-means fuzzy clustering minimizes either the distance or the objective squared error function (Kisi, 2015).

\subsection{Spatio-temporal modeling}

The use of GIS for the spatial modeling of many real-world phenomena toward implementation for sustainability (Childers et al., 2015; Lundgren and Kjellstrom, 2013) has attracted research 
230 attention. Spatial modelling acts like a critical tool to examine the nature or property of real-world

231 phenomena whether being sustained or not. Much of real-world phenomena are dynamic, and 232 involve spatial and temporal changes. Thus, the use of a GIS for temporal and spatial modeling 233 plays an important role in improving model visualization and tracking how much far from 234 sustainability indicators (Figure 4). The GIS is used for various purposes, such as creating the 235 required spatial data (geographical location) used as input for the prediction model. Using the 236 spatial functions generates a map related to the modeling phenomena to assess their behavior and 237 at different locations. Such spatial statistical functions as zonal statistics assess variation in 238 phenomena as well as minimum and maximum mean values at different locations. A geospatial 239 function, such as the interpolation method, enables the elimination of possible model defects (e.g., 240 data loss in some areas). Geostatistical analysis, such as trend analysis functions, provides 241 forecasting trends and patterns of phenomena.

242

243

244

\subsection{Model evaluation statistics}

Four statistics were used to evaluate the models: mean absolute error (MAE), root mean square error (RMSE), Nash-Sutcliffe efficiency (NSE), and the determination coefficient $\left(\mathrm{R}^{2}\right)$. RMSE, MAE, and NSE can be expressed as

$$
\begin{aligned}
& R M S E=\sqrt{\frac{1}{n} \sum_{i=1}^{n}\left(A T_{M, i}-A T_{o, i}\right)^{2}} \\
& M A E=\frac{1}{n} \sum_{i=1}^{n}\left|A T_{M, i}-A T_{o, i}\right| \\
& N S E=1-\frac{\sum_{i=1}^{n}\left(A T_{M, i}-A T_{o, i}\right)}{\sum_{i=1}^{n}\left(A T_{o, i}-\overline{A T_{o}}\right)}
\end{aligned}
$$

where $A T_{M}$ and $A T_{o}$ are modeled and observed air temperatures, respectively, $\mathrm{n}$ is the number of time steps, and $\overline{A T_{o}}$ is the mean observed air temperature. 
251 4. Application and Results

252

253

254

255

256

257

258

259

260

261

262

263

264

265

266

267

268

269

270

271

272

273

274

275

276

277

278

279

280

281

\subsection{Modeling long-term air temperatures using evolutionary fuzzy and neuro- fuzzy approaches}

Four hybrid fuzzy methods - evolutionary FG, ANFIS-GP, ANFIS-SC, and ANFIS-FCM-were compared in terms of predicting long-term air temperatures. The inputs of the models were latitude, longitude, altitude and month of the year. To train and test models, the data of 71 weather stations in Turkey were used. The entire dataset (the 70 stations $\times 12$ months $=840$ data items) was divided into three subsets. The first 23 stations were used in the first part, the second set of 23 for the second, and the other 24 stations were used for the last part. In the first application, training and testing were conducted using the first two parts (subsets) and the third part respectively; it was called model 1 (M1). In the second application, training was conducted using the second and third parts and testing was conducted using the first part, and was called model 2 (M2). In the last application, training was conducted using the first and third parts the testing was conducted using the second part, and was called model 3 (M3).

ANFIS-GP was applied to the datasets, and two and three Gaussian membership functions (MFs) were used to find the optimal one. More than three MFs led to worse results and memory-related problems. The number of iterations was varied from 10 to 100 with increments of 10 for each number of MFs. Different values of the radius were used (from 0.1 to 1 in increments of 0.1 ) for the ANFIS-SC model, and different numbers of clusters were used (from two to eight, incremented by one) for the ANFIS-FCM model. The numbers of iterations used were similar to those in the ANFIS-GP and ANFIS-SC methods. To test the FG models, the optimal number of MFs for the ANFIS-GP models were used. A total of 1,000 iterations and 100 members were used for the FG models. The optimal parameters and structures of the applied models are listed in Table 2. For example, 3-3-2-3,100 indicates an ANFIS-GP model with three, three, two, and three MFs for the four inputs (month of the year, latitude, longitude, and altitude) over 100 iterations. The number 1,100 indicates the value of the radii and the number of iterations of the ANFIS-SC model, the numbers of clusters and iterations of the ANFIS-FCM model were 5,100. "3-3-2-3, 1000, 100," indicating an FG model with three, three, two, and three MFs for the four inputs with 1,000 generations and a population of 100 .

Table 3 specifies the results of training and testing the models in terms of RMSE, MAE, NSE, and $\mathrm{R}^{2}$. In the training stage, the RMSE of the FG model ranged from 1.59 to 1.89 , whereas that of 
282

ANFIS-GP, ANFIS-SC, and ANFIS-FCM was in the range 2.16-2.95, 1.14-1.45, and 6.13-6.93, respectively. Similar ranges were observed for the MAE, NSE, and $\mathrm{R}^{2}$. The ranges and means reveal that the ANFIS-SC was the most accurate in terms of approximating long-term air temperatures followed by the FG. ANFIS-FCM yielded the worst results in this stage. In the test stage, however, the ranges of RMSE, MAE, NSE, and R ${ }^{2}$ of the FG models were 1.63-3.26, 1.23$2.08,0.868-0.967$, and $0.882-0.967$, respectively, which were superior to the those of the other models. The average RMSE, MAE, NSE, and $\mathrm{R}^{2}$ of the optimal FG models $(2.32,1.59,0.925$, and 0.935) were also higher than those of the ANFIS-GP (2.91, 2.28, 0.890, 0.898), ANFIS-SC (5.41, $3.42,0.539,0.768)$, and ANFIS-FCM (12.5, 8.32, 0.239, 0.250) models. Among the neuro-fuzzy models, ANFIS-GP obtained the highest accuracy. In terms of RMSE, MAE, NSE, and $\mathrm{R}^{2}$, the FG model enhanced the accuracy of ANFIS-GP by $20 \%, 30 \%, 4 \%$, and $4 \%$, respectively.

A graphical comparison of the four methods is provided in Figures 5-7 for M1, M2, and M3. The obvious finding from Figure 4 is that the estimates of the FG model were closer to the corresponding observed temperatures than those of the ANFIS-GP, ANFIS-SC, and ANFIS-FCM models. Considerable under/over-estimations were observed in the ANFIS-FCM model. The scatterplots show that the fit line equation of the FG model was $y=0.9910 x-0.906$, closer to the exact line $(\mathrm{y}=\mathrm{x})$ with a higher $\mathrm{R}^{2}$ than the other three models. ANFIS-GP was better than the other two neuro-fuzzy models. Similar trends were seen for M2 and M3 (see Figures 6-7).

\subsection{Spatial modeling of long-term air temperatures using GIS}

Air temperature is a spatio-temporal phenomenon, and thus changes with time and place. Based on their capabilities, GIS spatial functions can be used to improve the model. The GIS can be used to provide additional input for air temperature modeling in the form of spatial data (latitude and longitude). This spatial modeling leads to greater flexibility in the proposed model and renders it more adaptable for practical use. Moreover, the GIS is used to create temperature maprelated locations to enable better visualization and interpretation of the outputs.

A classified temperature mapping enables a comparison of the variation in temperature ranges of all methods with respect to M1 (Figure 8), M2 (Figure 9), and M3 (Figure 10). The lowest temperature ranges according to the classified temperature map in M1 were ANFIS-SC: 4.528.74, ANFIS-FCM: 6.14-8.95, ANFIS-GP: 8.45-10.22, and FG-FUZZY-G: 8.94-10.47. The 
312 maximum temperatures were ANFIS-SC: 18.82-22.75, ANFIS-FCM: 17.45-20.21, ANFIS-GP:

313 16.02-18.05, and FG-FUZZY-G: 16.75-18.47. The lowest temperatures ranges according to M2

314 were ANFIS-SC: -5.09- -3.33, ANFIS-FCM: -85.50- -6, ANFIS-GP: 7.22-9.34, and FG-

315 FUZZY-G: 4.46-7.62, and the maximum temperatures were ANFIS-SC: $37.08--48.67$, ANFIS-

316 FCM: 13.38-24.13, ANFIS-GP: 16.35- 18.47, and FG-FUZZY-G: 15.21-17.51. The lowest temperature ranges in M3 were ANFIS-SC: 8.15-10.75, ANFIS-FCM: 4.60-9.20, ANFIS-GP: 10.23-11.75, and FG-FUZZY-G: 7.96-10.29), and the maximum temperatures were ANFIS-SC: 18.08-19.98, ANFIS-FCM: 23.60-26.73, ANFIS-GP: 17.43-19.23, and FG-FUZZY-G: 16.0217.48 .

Furthermore, the temperature map helps experts evaluate the temperature in different locations to identify places with maximum or minimum temperatures. For example, in M1, Osmaniye, in M2, Adana, and in M3, Hatay had the highest temperatures in the best FG method. The unique functionality of other GISs in this section helps address defects in the proposed model. Following this, if there is information loss in some areas, the maps use interpolation functions to yield the temperature.

\section{Discussion}

As mentioned in the previous section, the ANFIS-GP has memory-related problems when it has much membership functions (more than 3 in this study). In fact, this also changes with respect to input numbers. In this study, 4 inputs were used and, in this case, the use of 4 membership functions causes memory problem. This is due to the fact that ANFIS-GP consider all rules combinations, and it therefore has much more premise parameters, which show the membership functions' shape and location and consequent parameters that compose the equations of considered rules. However, the main advantage of this method is that it is more flexible because of high number of weights compared to other ANFIS methods, ANFIS-SC and ANFIS-FCM. The main advantages of the ANFIS-SC and ANFIS-FCM methods are the use of less parameters or weights because they use clustering algorithms, and they can therefore optimize rule or membership functions' numbers. However, this property may cause inappropriate learning of these methods compared to ANFISGP.

The FG model was found to be the best method in modelling long-term temperatures, followed by the ANFIS-GP method. The FG also uses all rules combinations similar to ANFIS-GP and 
342 therefore, it has much more premise parameters which show the membership functions' shape and

343 location and consequent parameters. The main advantage of the FG due to its evolutionary training 344 algorithm (genetic algorithm, GA). In ANFIS-GP, gradient descent (GD) algorithm is utilized for 345 the optimization of membership functions' parameters (premise parameters). The GD can be 346 trapped into local optima, while this does not occur for the GA algorithm.

\section{Conclusions}

349

350

351

352

353

354

355

356

In this paper, the capabilities of evolutionary fuzzy genetics were compared with three neuro-fuzzy techniques in terms of estimating long-term air temperatures for sustainability. Data from 71 stations from Turkey were used and divided into three equal parts. The applied models were tested using each part. Each method was hence tested three times with all the data. Finally, a GIS was used to produce air temperature maps based on the results of the optimal models. Three main results can be drawn from the application:

i- $\quad$ The evolutionary FG model is superior to the ANFIS-GP, ANFIS-SC, and ANFISFCM at modeling long-term air temperatures.

ii- $\quad$ Of the neuro-fuzzy methods, the ANFIS-GP outperformed the ANFIS-SC and ANFISFCM.

iii- $\quad$ The accuracy of the best neuro-fuzzy model, the ANFIS-GP, in terms of RMSE, MAE, NSE and $\mathrm{R}^{2}$ increased by $20 \%, 30 \%, 4 \%$, and $4 \%$, respectively, using the FG model.

\section{Funding}

This research was supported by the MSIT (Ministry of Science and ICT), Korea, under the ITRC (Information Technology Research Center) support program (IITP-2019-2016-0-00312).

\section{References}

Abdel-Aal, R.E.: Hourly temperature forecasting using abductive networks. Engineering Applications of Artificial Intelligence, 17(5):543-556, 2004. 
Abraham, A. and Jain, L.: Evolutionary Multiobjective Optimization: Theoretical Advances and Applications, Springer, London, 1-6 pp., 2005.

Aijun, L., Hejun, L., Kezhi, L. and Zhengbing, G.: Applications of neural networks and genetic algorithms to CVI processes in carbon/carbon composites. Acta Mater, 52(2):299-305, 2004.

Ali-Nezhad, F.M. and Eskandari, H.: Effect of architectural design of greenhouse on solar radiation interception and crops growth conditions. Int. J. Agric. Crop Sci., 4(3):122-127, 2012.

Ayvaz, M.T., Karahan, H. and Aral, M.M.: Aquifer parameter and zone structure estimation using kernel-based fuzzy c-means clustering and genetic algorithm. J Hydrol, 343(3-4):240-253, 2007.

Benavides, R., Montes, F., Rubio, A. and Osoro, K.: Geostatistical modelling of air temperature in a mountainous region of Northern Spain. Agricultural and Forest Meteorology, 146(3-4):173-188, 2007.

Bilgili, M. and Sahin, B.: Prediction of long-term monthly temperature and rainfall in Turkey. Energy Sources, Part A: Recovery, Utilization, and Environmental Effects, 32(1):60-71, 2009.

Chattopadhyay, S., Jhajharia, D. and Chattopadhyay, G.: Univariate modelling of monthly maximum temperature time series over northeast India: neural network versus Yule-Walker equation based approach. Meteorol. Appl., 18(1):70-82, 2011.

Brunetti, M. , Maugeri, M. , Nanni, T. , Simolo, C. and Spinoni, J. (2014), High-resolution temperature climatology for Italy: interpolation method intercomparison. Int. J. Climatol., 34: 1278-1296. doi:10.1002/joc.3764

Childers, D., Cadenasso, M., Grove, J., Marshall, V., McGrath, B. and Pickett, S.: An ecology for cities: A transformational nexus of design and ecology to advance climate change resilience and urban sustainability. Sustainability, 7(4):3774-3791, 2015.

Chiu, S.L.: Fuzzy model identification based on cluster estimation. J Intell Fuzzy Syst, 2(3):267-278, 1994.

Chuanyan, Z., Zhongren, N. and Guodong, C.: Methods for modelling of temporal and spatial distribution of air temperature at landscape scale in the southern Qilian mountains, China. Ecological Modelling, 189(1-2):209-220, 2005.

Cobaner, M.: Evapotranspiration estimation by two different neuro-fuzzy inference systems. J Hydrol, 398(3-4):292302, 2011.

Cobaner, M., Citakoglu, H., Kisi, O. and Haktanir, T.: Estimation of mean monthly air temperatures in Turkey. Computers and Electronics in Agriculture, 109:71-79, 2014.

Goodale, C.L., Aber, J.D. and Ollinger, S.V. Mapping monthly precipitation, temperature, and solar radiation for Ireland with polynomial regression and a digital elevation model. Clim. Res., 10(1):35-49, 1998.

Gonzalez-Hidalgo, J. C., Peña-Angulo, D. , Brunetti, M. and Cortesi, N. (2015), MOTEDAS: a new monthly temperature database for mainland Spain and the trend in temperature (1951-2010). Int. J. Climatol., 35: 44444463. doi:10.1002/joc.4298

Hasanuzzaman, M., Nahar, K. and Fujita, M.: Extreme temperature responses, oxidative stress and antioxidant defense in plants. In Abiotic stress-Plant responses and applications in agriculture, ISBN: 978-953-51-1024-8, InTech, doi: http://dx.doi.org/10.5772/54833, 2013. 
Jang, J.S.: ANFIS: adaptive-network-based fuzzy inference system. IEEE Trans. Syst. Man Cyber., 23(3):665-685, 1993.

Jang, J.-S.R., Sun, C.-T., and Mizutani, E.: Neuro-Fuzzy and Soft Computing: A Computational Approach to Learning and Machine Intelligence. Prentice Hall, Upper Saddle River, New Jersey, USA,1997.

Jean, M.D., Lin, B.T. and Chou, J.H.: Design of a fuzzy logic approach based on genetic algorithms for robust plasmasprayed zirconia depositions. Acta materialia, 55(6):1985-1997, 2007.

Khosravi, A., Koury, R. N. N., Machado, L., \& Pabon, J. J. G. (2018). Prediction of hourly solar radiation in Abu Musa Island using machine learning algorithms. Journal of Cleaner Production, 176, 63-75.

Kisi, O. and Cengiz, T.M.: Fuzzy genetic approach for estimating reference evapotranspiration of Turkey: Mediterranean region. Water Resour Manage, 27(10):3541-3553, 2013.

Kisi, O.: Streamflow forecasting and estimation using least square support vector regression and adaptive neuro-fuzzy embedded fuzzy c-means clustering. Water Resour Manage, 29(14):5109-5127, 2015.

Kisi, O. and Shiri, J.: Prediction of long-term monthly air temperature using geographical inputs. Int. J. Climatol., 34(1):179-186, 2014.

Kiszka, J. B., Kochanskia, M. E. and Sliwiska, D. S.: The influence of some fuzzy implication operators on the accuracy of fuzzy model, Part I. Fuzzy Set and Syst, 15, 111-128, 1985a.

Kiszka, J. B. Kochanska, M. E. and Sliwinska, D. S.: The influence of some fuzzy implication operators on the accuracy of a fuzzy model, Part II. Fuzzy Set and Syst, 15, 223-240, 1985b.

Kosko, B. and Toms, M.: Fuzzy thinking: The new science of fuzzy logic, New York: Hyperion, 1-350pp.,1993.

Ninyerola, M., Pons, X. and Roure, J.M.: A methodological approach of climatological modelling of air temperature and precipitation through GIS techniques. Int. J. Climatol., 20(14):1823-1841, 2000.

Lundgren, K. and Kjellstrom, T.: Sustainability challenges from climate change and air conditioning use in urban areas. Sustainability, 5(7):3116-3128, 2013.

Ortiz Jr, F., Simpson, J.R., Pignatiello Jr, J.J. and Heredia-Langner, A.: A genetic algorithm approach to multipleresponse optimization. J Quality Eng, 36(4):432-450, 2004.

Rosenzweig, C. and Liverman, D.: Predicted effects of climate change on agriculture: A comparison of temperate and tropical regions. Dalam Global Climate Change: Implications, Challenges, and Mitigation Measures. Dalam SK Majumdar (Ed.) The Pennsylvania Academy of Sciences. PA, 342-61 pp., 1992.

Russell, S.O. and Campbell, P.F.: Reservoir operating rules with fuzzy programming. J Water Resour Plann Manage ASCE, 122(3):165-170, 1996.

Sanikhani, H. and Kisi, O.: River flow estimation and forecasting by using two different adaptive neuro-fuzzy approaches. Water Resour Manage, 26(6):1715-1729, 2012.

Şahin, M.: Modelling of air temperature using remote sensing and artificial neural network in Turkey. Adv. Space Res. h, 50(7):973-985, 2012.

Şen, Z.: Fuzzy algorithm for estimation of solar irradiation from sunshine duration. Sol. Energy, 63(1):39-49, 1998.

Serrano-Notivoli, R., Beguería, S., and De Luis, M.: STEAD: A high-resolution daily gridded temperature dataset for Spain, Earth Syst. Sci. Data Discuss., https://doi.org/10.5194/essd-2019-52, in review, 2019 
441 442

Shank, D.B., Hoogenboom, G. and McClendon, R.W.: Dewpoint temperature prediction using artificial neural networks. Journal of applied meteorology and climatology, 47(6):1757-1769, 2008.

Smith, B.A., McClendon, R.W. and Hoogenboom, G.: An Enhanced Artificial Neural Network for Air Temperature Prediction. In IEC (Prague), 7-12 pp., 2005.

Toros, H.: Spatio-temporal precipitation change assessments over Turkey. International Journal of Climatology, 32(9):1310-1325, 2012.

Tsai, J.T., Liu, T.K. and Chou, J.H.: Hybrid Taguchi-genetic algorithm for global numerical optimization. IEEE Trans Evolut Comput, 8(4):365-377, 2004.

Vernieuwe, H., Georgieva, O., De Baets, B., Pauwels, V.R., Verhoest, N.E. and De Troch, F.P.: Comparison of datadriven Takagi-Sugeno models of rainfall-discharge dynamics. Journal of Hydrology, 302(1-4):173-186, 2005.

Yager, R.R. and Filev, D.P.: Approximate clustering via the mountain method. IEEE Trans Syst Man Cybern, 24(8):1279-1284, 1994.

Zadeh, L.A.: Fuzzy sets. Information and control, 8(3):338-353, 1965.

Zhu, S., Heddam, S., Nyarko, E. K., Hadzima-Nyarko, M., Piccolroaz, S., \& Wu, S. (2019). Modeling daily water temperature for rivers: comparison between adaptive neuro-fuzzy inference systems and artificial neural networks models. Environmental Science and Pollution Research, 26(1), 402-420. 
Table $\mathbf{1}$ (on next page)

Table 1 
2 Table 1. Summary of the geographical information of the studied weather stations (Kisi et al. 2017)

\begin{tabular}{|c|c|c|c|c|c|c|c|c|c|}
\hline Station & $\begin{array}{l}\text { Lat. } \\
\left({ }^{\circ} \mathrm{N}\right)\end{array}$ & $\begin{array}{l}\text { Long. } \\
\left({ }^{\circ} \mathrm{W}\right)\end{array}$ & $\begin{array}{l}\text { Alt. } \\
\text { (m) }\end{array}$ & ${ }^{*} \mathrm{~T}\left({ }^{\circ} \mathrm{C}\right)$ & Station & $\begin{array}{l}\text { Lat. } \\
\left({ }^{\circ} \mathrm{N}\right)\end{array}$ & $\begin{array}{l}\text { Long. } \\
\left({ }^{\circ} \mathrm{W}\right)\end{array}$ & $\begin{array}{l}\text { Alt. } \\
\text { (m) }\end{array}$ & ${ }^{*} \mathrm{~T}\left({ }^{\circ} \mathrm{C}\right)$ \\
\hline Adana & 37 & 35.32 & 27 & 19.12 & K.maras & 37.3 & 40.77 & 572 & 16.81 \\
\hline Adiyaman & 37.76 & 38.27 & 672 & 17.24 & Karabuk & 41.2 & 32.62 & 259 & 13.33 \\
\hline Afyon & 38.74 & 30.55 & 1034 & 11.28 & Karaman & 37.17 & 33.22 & 1025 & 11.88 \\
\hline Agri & 39.72 & 43.05 & 1632 & 6.18 & Kars & 40.59 & 43.08 & 400 & 4.81 \\
\hline Aksaray & 38.37 & 34.03 & 965 & 12.02 & Kastamonu & 41.37 & 33.77 & 800 & 9.73 \\
\hline Amasya & 40.65 & 35.83 & 412 & 13.63 & Kayseri & 38.72 & 35.49 & 1093 & 10.44 \\
\hline Ankara & 39.97 & 32.86 & 891 & 11.98 & Kirikkale & 39.84 & 33.52 & 748 & 12.57 \\
\hline Antalya & 36.9 & 30.79 & 54 & 18.40 & Kirklareli & 41.74 & 27.22 & 232 & 13.20 \\
\hline Ardahan & 41.11 & 42.7 & 1829 & 3.75 & Kirsehir & 39.16 & 34.15 & 1007 & 11.35 \\
\hline Artvin & 41.18 & 41.82 & 628 & 12.03 & Kilis & 36.72 & 37.12 & 638 & 17.10 \\
\hline Aydin & 37.84 & 27.84 & 56 & 17.63 & Konya & 37.99 & 32.56 & 1031 & 11.58 \\
\hline Balikesir & 39.63 & 27.92 & 102 & 14.55 & Kutayha & 39.42 & 29.99 & 969 & 10.75 \\
\hline Bartin & 41.62 & 32.35 & 30 & 12.63 & Malatya & 38.35 & 38.31 & 948 & 13.74 \\
\hline Batman & 37.89 & 41.12 & 540 & 16.51 & Manisa & 38.61 & 37.4 & 71 & 16.98 \\
\hline Bayburt & 40.25 & 40.43 & 1584 & 6.93 & Mardin & 37.31 & 40.73 & 1040 & 16.15 \\
\hline Bilecik & 40.14 & 29.97 & 539 & 12.50 & Mugla & 37.29 & 28.37 & 646 & 15.01 \\
\hline Bingol & 38.88 & 40.49 & 11.77 & 11.95 & Mus & 38.74 & 41.49 & 1320 & 9.71 \\
\hline Bitlis & 38.39 & 42.12 & 1573 & 9.53 & Nigde & 37.97 & 34.69 & 1211 & 11.08 \\
\hline Bolu & 40.74 & 31.6 & 743 & 10.53 & Osmaniye & 37.1 & 36.25 & 94 & 18.24 \\
\hline Burdur & 37.72 & 30.29 & 967 & 13.18 & Rize & 41.04 & 40.5 & 9 & 14.23 \\
\hline Bursa & 40.23 & 29.01 & 100 & 14.56 & Sakarya & 40.77 & 30.39 & 31 & 14.44 \\
\hline Canakkale & 40.15 & 26.41 & 6 & 15.01 & Samsun & 41.35 & 36.24 & 4 & 14.38 \\
\hline Cankiri & 40.61 & 33.61 & 751 & 11.18 & Siirt & 37.93 & 41.94 & 896 & 16.11 \\
\hline Corum & 40.54 & 34.94 & 776 & 10.57 & Sinop & 42.02 & 35.15 & 32 & 14.09 \\
\hline Denizli & 37.76 & 29.09 & 425 & 16.21 & Sivas & 39.74 & 37.02 & 1285 & 9.08 \\
\hline Elazig & 38.67 & 39.22 & 990 & 13.03 & S.urfa & 37.16 & 38.79 & 549 & 18.38 \\
\hline Erzincan & 39.74 & 39.5 & 1218 & 10.89 & Sirnak & 37.52 & 42.45 & 1350 & 14.13 \\
\hline Erzurum & 39.95 & 41.17 & 17.58 & 5.40 & Tekirdag & 40.99 & 27.49 & 3 & 13.96 \\
\hline Eskisehir & 39.78 & 30.58 & 786 & 10.84 & Tokat & 40.3 & 36.56 & 608 & 12.48 \\
\hline Gaziantep & 37.07 & 37.39 & 855 & 15.07 & Trabzon & 41 & 39.78 & 39 & 14.68 \\
\hline Giresun & 40.92 & 38.39 & 37 & 14.53 & Tunceli & 39.1 & 39.55 & 978 & 12.83 \\
\hline Gumushane & 40.46 & 39.47 & 1219 & 9.55 & Usak & 38.67 & 29.4 & 919 & 12.51 \\
\hline Hakkari & 37.57 & 43.75 & 1728 & 10.26 & Van & 38.49 & 43.39 & 1661 & 9.24 \\
\hline Hatay & 36.36 & 36.28 & 82 & 18.26 & Yalova & 40.66 & 29.27 & 4 & 14.67 \\
\hline Igdir & 39.92 & 44.06 & 858 & 12.08 & Yozgat & 39.82 & 34.81 & 1298 & 8.97 \\
\hline Istanbul & 40.98 & 28.82 & 33 & 15.01 & & & & & \\
\hline
\end{tabular}


Table 2 (on next page)

Table 2 
2 Table 2. Optimal parameters and structures of the ANFIS-GP, ANFIS-SC, ANFIS-FCM and FG models

\begin{tabular}{ccccc}
\hline Model & ANFIS-GP & ANFIS-SC & ANFIS-FCM & FG \\
\hline M1 & $3-3-2-3,100$ & 1,100 & 5,100 & $3-3-2-3,1000,100$ \\
M2 & $3-2-2-2,100$ & 1,100 & 8,90 & $3-2-2-2,1000,100$ \\
M3 & $3-3-2-3,100$ & 1,100 & 7,100 & $3-3-2-3,1000,100$ \\
\hline
\end{tabular}

3 
Table 3 (on next page)

Table 3 
Table 3. Training and testing results of the FG, ANFIS-GP, ANFIS-SC and ANFIS-FCM models

\begin{tabular}{|c|c|c|c|c|c|c|c|c|c|c|c|c|c|c|c|c|c|}
\hline \multirow[b]{2}{*}{ Process } & \multirow[b]{2}{*}{ Model } & \multicolumn{5}{|c|}{ FG } & \multicolumn{3}{|c|}{ ANFIS-GP } & \multicolumn{5}{|c|}{ ANFIS-SC } & \multicolumn{3}{|c|}{ ANFIS-FCM } \\
\hline & & $\begin{array}{c}\text { RMSE } \\
\left({ }^{\circ} \mathrm{C}\right)\end{array}$ & $\begin{array}{c}\text { MAE } \\
\left({ }^{\circ} C\right) \\
\end{array}$ & $N S E$ & $R^{2}$ & $\begin{array}{c}\text { RMSE } \\
\left({ }^{\circ} \mathrm{C}\right)\end{array}$ & $\begin{array}{l}\text { MAE } \\
\left({ }^{\circ} C\right) \\
\end{array}$ & $N S E$ & $R^{2}$ & $\begin{array}{c}\text { RMSE } \\
\left({ }^{\circ} \mathrm{C}\right)\end{array}$ & $\begin{array}{c}\text { MAE } \\
\left({ }^{\circ} C\right) \\
\end{array}$ & $N S E$ & $R^{2}$ & $\begin{array}{c}\text { RMSE } \\
\left({ }^{\circ} \mathrm{C}\right)\end{array}$ & $\begin{array}{c}\text { MAE } \\
\left({ }^{\circ} C\right) \\
\end{array}$ & $N S E$ & $R^{2}$ \\
\hline \multirow{4}{*}{ Training } & M1 & 1.89 & 1.31 & 0.955 & 0.956 & 2.47 & 1.98 & 0.924 & 0.924 & 1.24 & 0.95 & 0.981 & 0.981 & 6.66 & 5.48 & 0.448 & 0.448 \\
\hline & M2 & 2.19 & 1.43 & 0.937 & 0.938 & 2.95 & 2.26 & 0.886 & 0.886 & 1.45 & 1.10 & 0.972 & 0.972 & 6.93 & 5.81 & 0.373 & 0.373 \\
\hline & M3 & 1.59 & 1.25 & 0.967 & 0.967 & 2.16 & 1.83 & 0.938 & 0.938 & 1.14 & 0.87 & 0.983 & 0.983 & 6.13 & 5.06 & 0.504 & 0.504 \\
\hline & Mean & 1.89 & 1.33 & 0.953 & 0.954 & 2.53 & 2.02 & 0.916 & 0.916 & 1.28 & 0.973 & 0.979 & 0.979 & 6.57 & 5.45 & 0.442 & 0.442 \\
\hline \multirow{4}{*}{ Testing } & M1 & 2.08 & 1.45 & 0.940 & 0.955 & 2.74 & 2.26 & 0.896 & 0.904 & 3.93 & 2.52 & 0.78 & 0.820 & 7.53 & 6.17 & 0.209 & 0.253 \\
\hline & M2 & 1.63 & 1.23 & 0.967 & 0.967 & 2.68 & 2.10 & 0.910 & 0.912 & 9.09 & 5.64 & -0.036 & 0.602 & 22.3 & 12.5 & -5.22 & 0.119 \\
\hline & M3 & 3.26 & 2.08 & 0.868 & 0.882 & 3.31 & 2.47 & 0.864 & 0.878 & 3.21 & 2.09 & 0.872 & 0.882 & 7.67 & 6.30 & 0.269 & 0.379 \\
\hline & Mean & 2.32 & 1.59 & 0.925 & 0.935 & 2.91 & 2.28 & 0.890 & 0.898 & 5.41 & 3.42 & 0.539 & 0.768 & 12.5 & 8.32 & 0.239 & 0.250 \\
\hline
\end{tabular}


Figure 1

Figure 1

Meteorological stations distribution in Turkey (the map was provided by the State State Hydraulic Works (DSI), see http://en.dsi.gov.tr/about-dsi-)

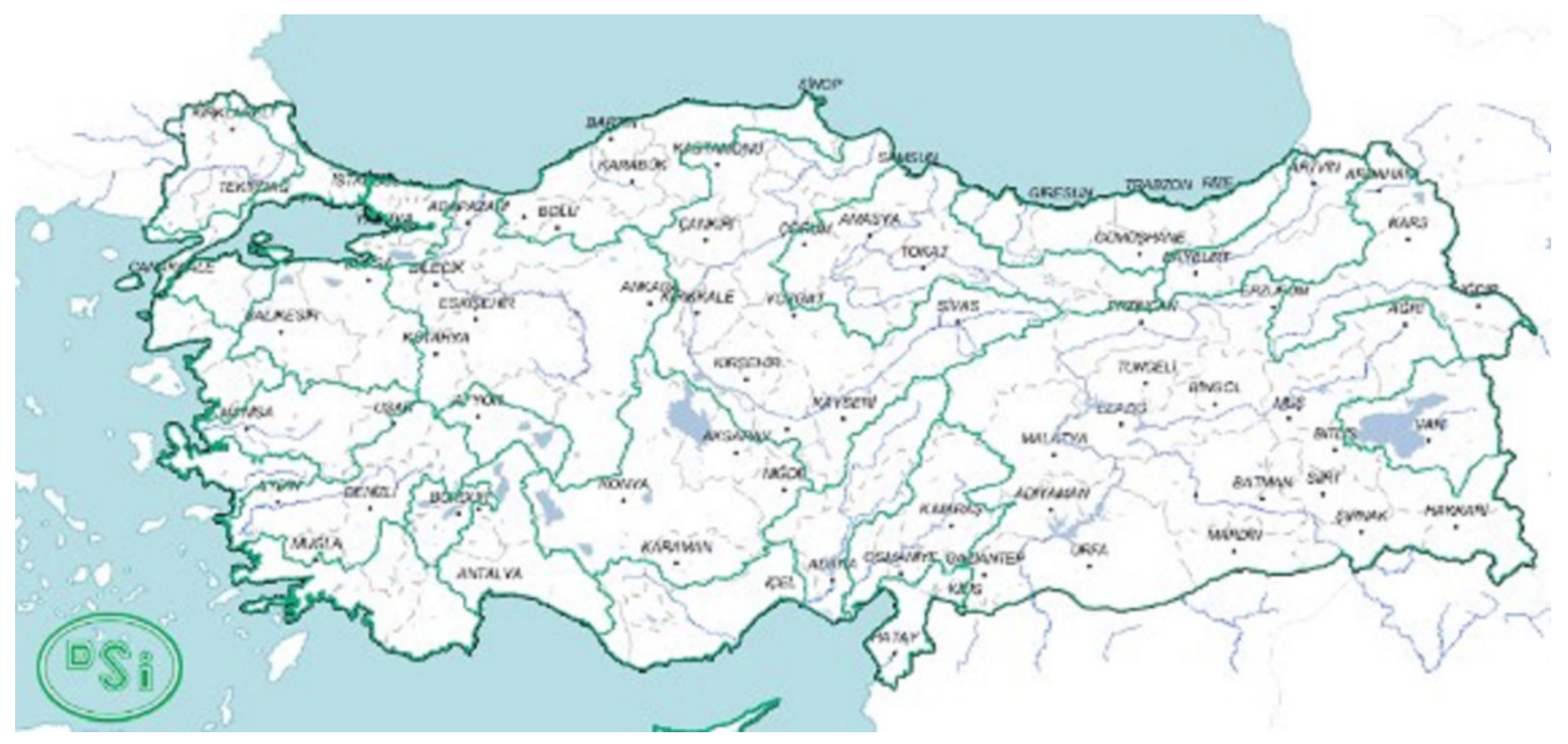


Figure 2

Figure 2

A typical fuzzy inference system

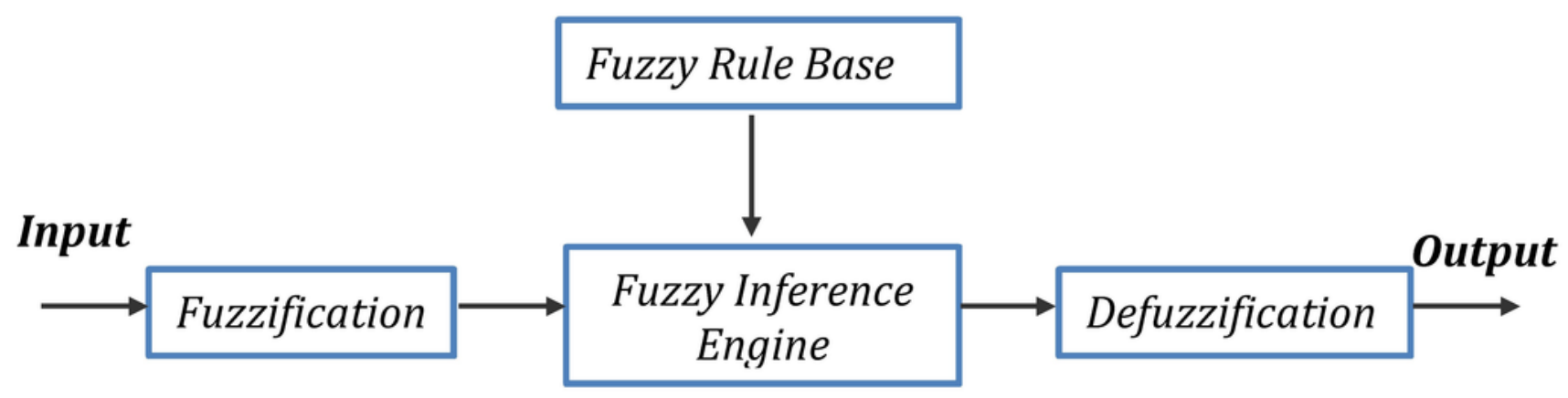


Figure 3

Figure 3

ANFIS model for temperature prediction

Layer 1

Layer 2

Layer 3

Layer 4

Layer 5

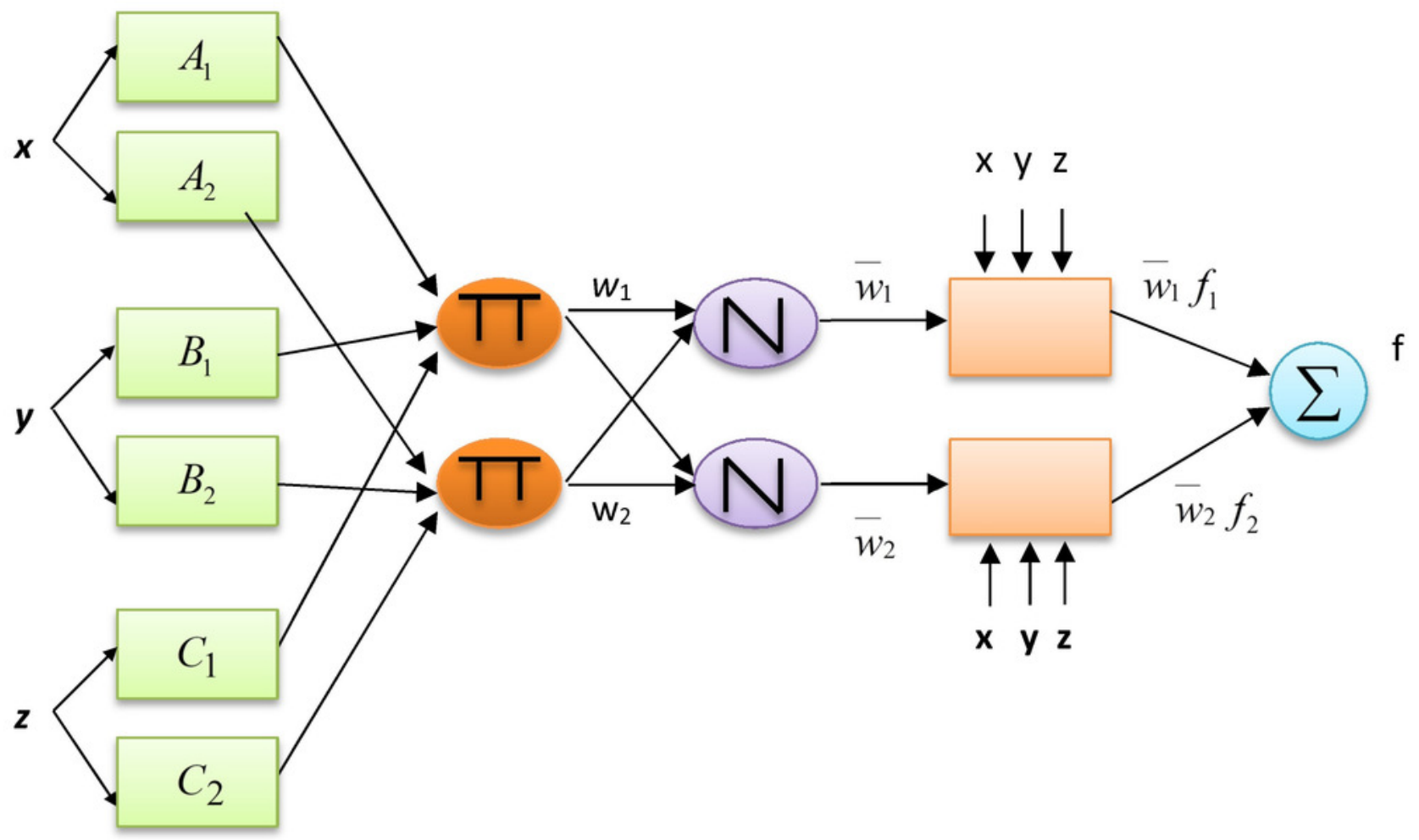


Figure 4

Figure 4

Spatial temporal modeling

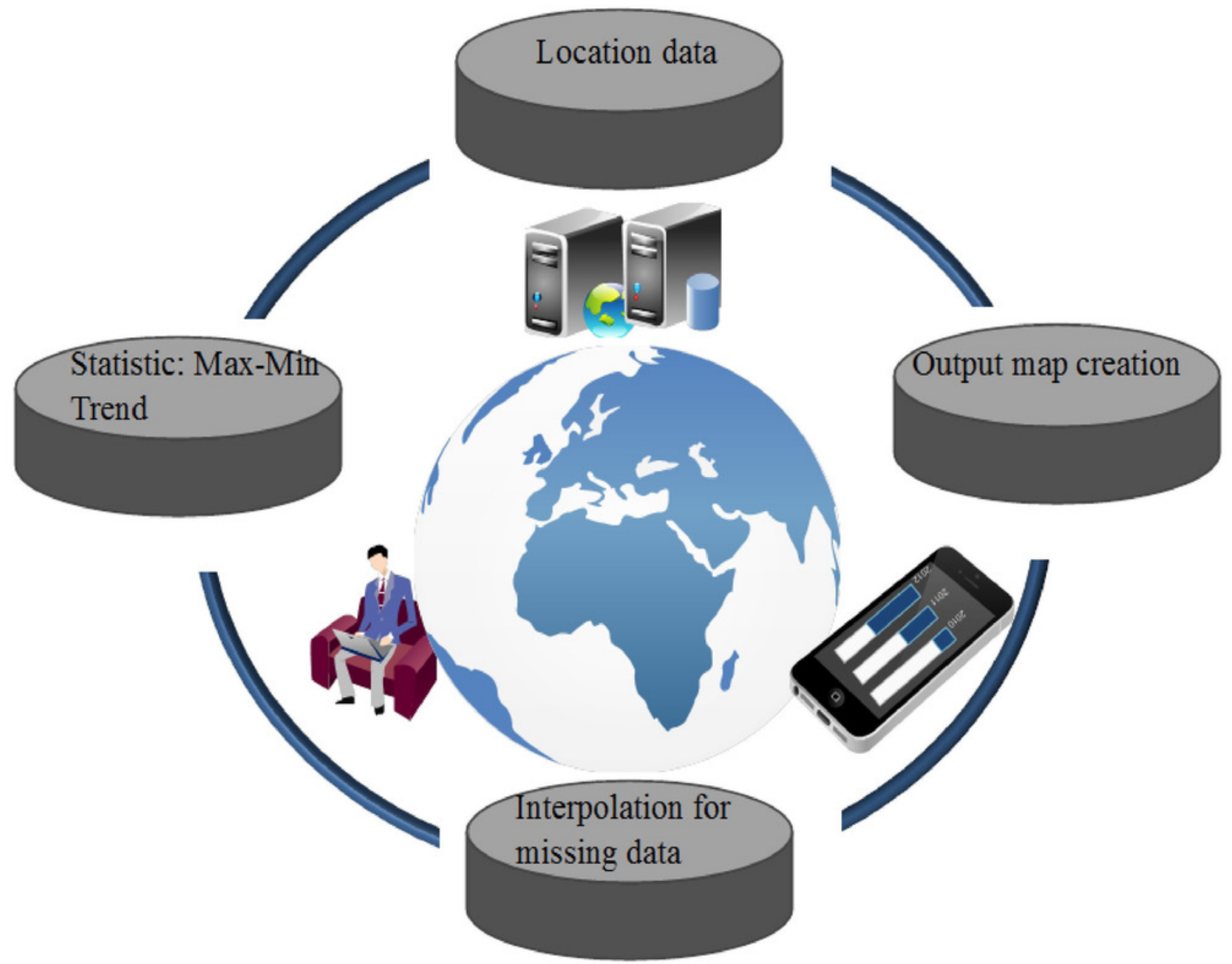




\section{Figure 5}

Figure 5.

Observed and predicted air temperatures by FG, ANFIS-GP, ANFIS-SC and ANFIS-FCM models

- M1 models; time variation graphs of (a) FG, (b) ANFIS-GP, (c) ANFIS-SC and (d) ANFIS-FCM and scatterplots of (e) FG, (f) ANFIS-GP, (g) ANFIS-SC and (h) ANFIS-FCM 

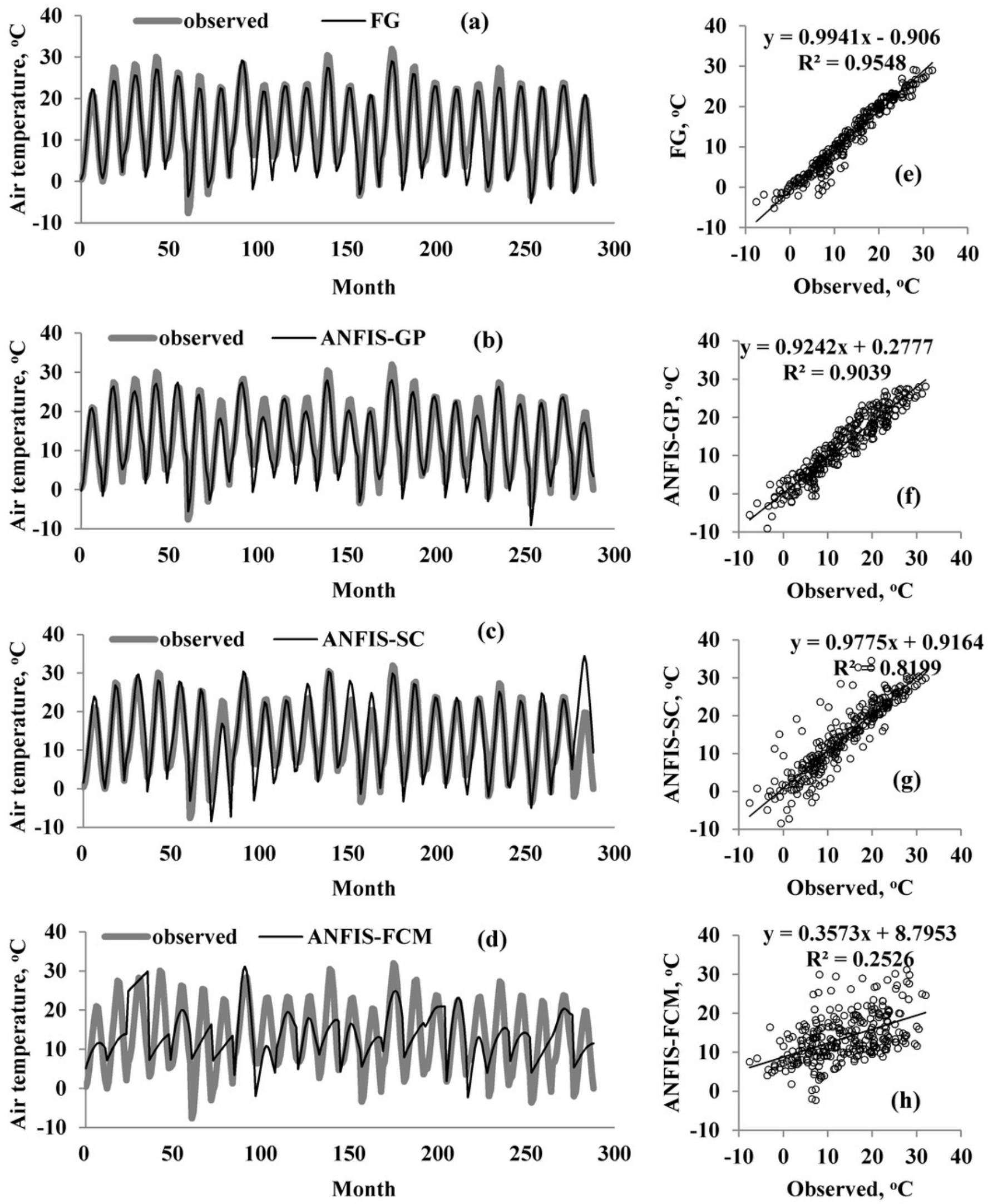
Figure 6

Figure 6.

Observed and predicted air temperatures by FG, ANFIS-GP, ANFIS-SC and ANFIS-FCM models

- M2 models; time variation graphs of (a) FG, (b) ANFIS-GP, (c) ANFIS-SC and (d) ANFIS-FCM and scatterplots of (e) FG, (f) ANFIS-GP, (g) ANFIS-SC and (h) ANFIS-FCM 

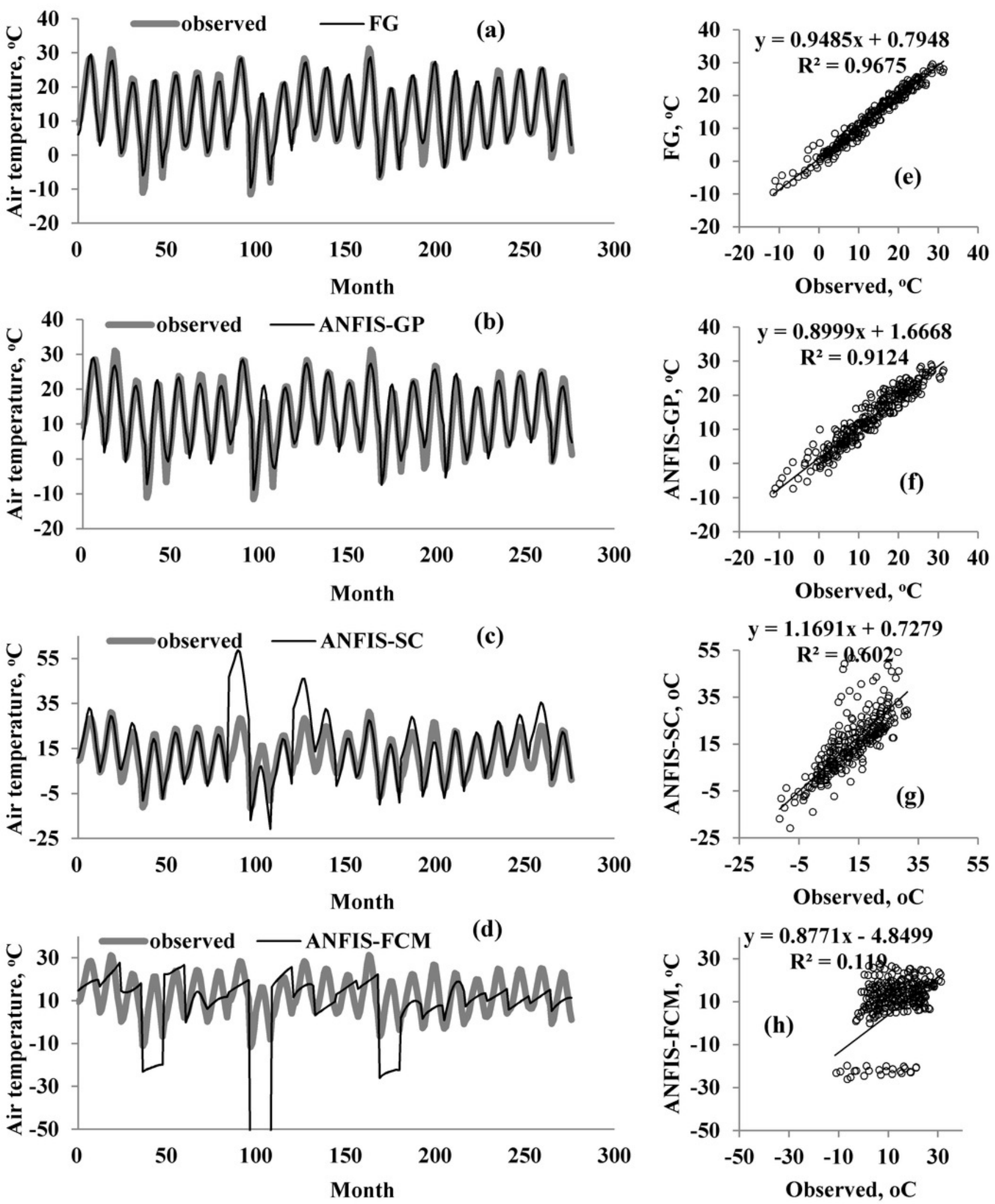


\section{Figure 7}

Figure 7.

Observed and predicted air temperatures by FG, ANFIS-GP, ANFIS-SC and ANFIS-FCM models

- M3 models; time variation graphs of (a) FG, (b) ANFIS-GP, (c) ANFIS-SC and (d) ANFIS-FCM and scatterplots of (e) FG, (f) ANFIS-GP, (g) ANFIS-SC and (h) ANFIS-FCM 

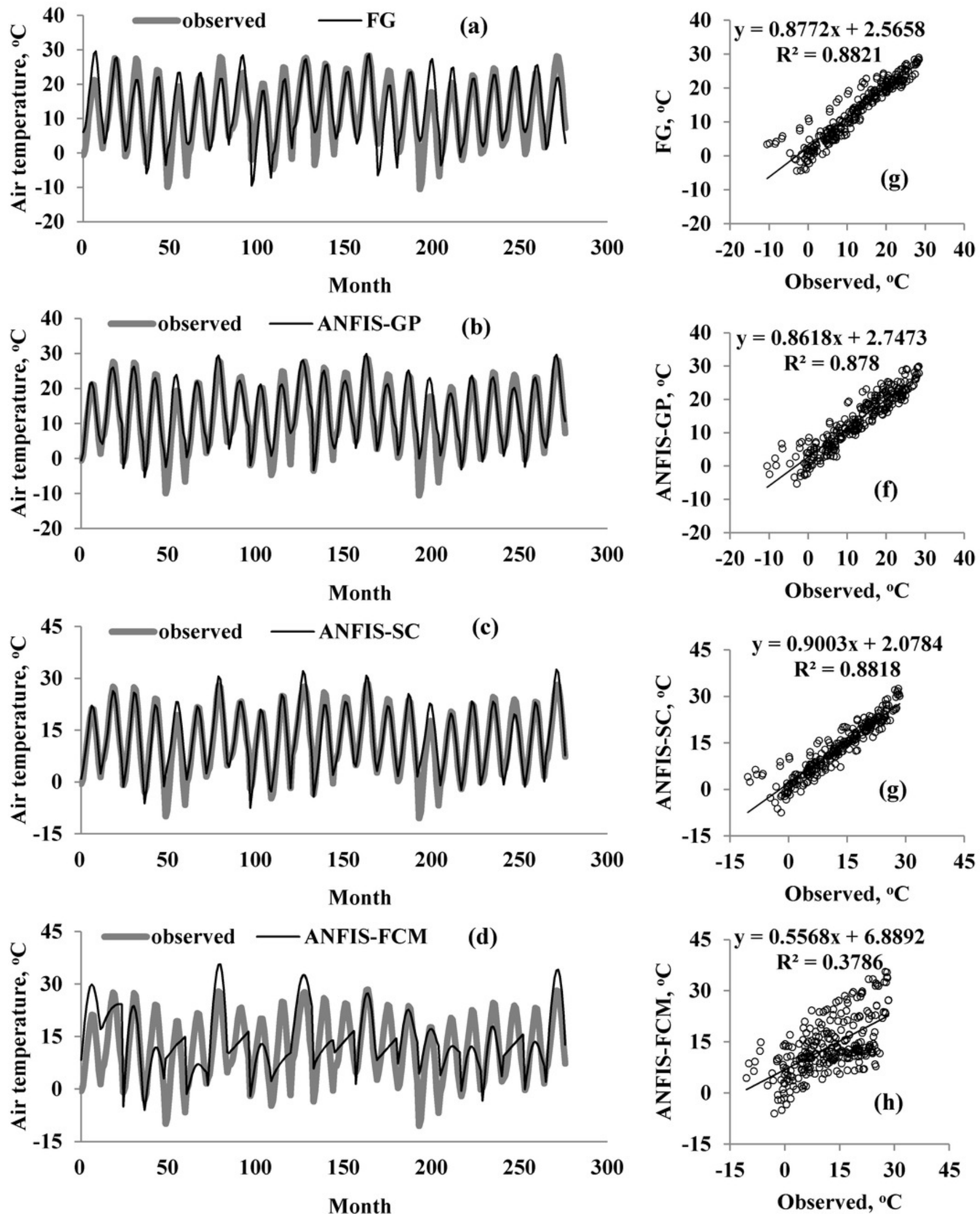
Figure 8

Figure 8.

M1 model output maps for (a) ANFIS-SC, (b) ANFIS-GP, (c) ANFIS-FCM and (d) FG

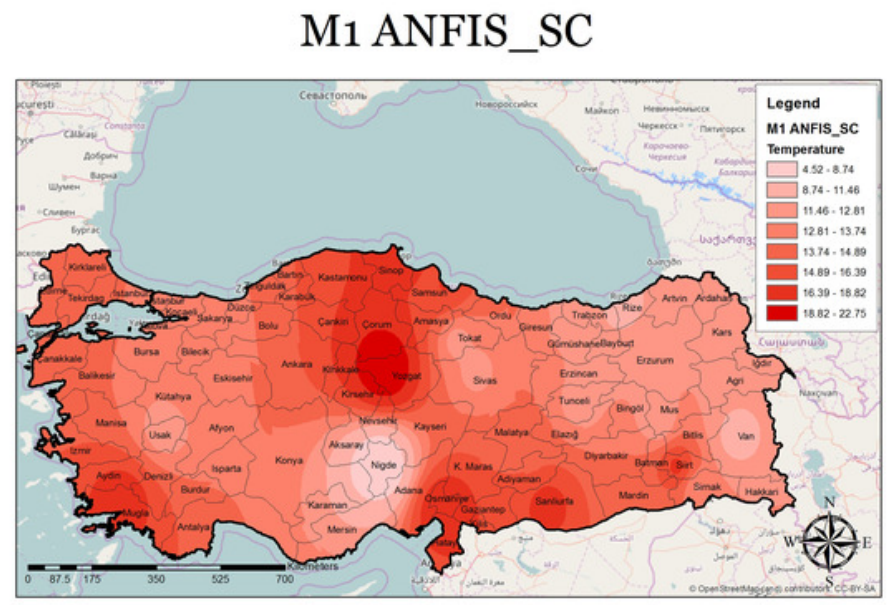

(a)

M1 ANFIS_FCM

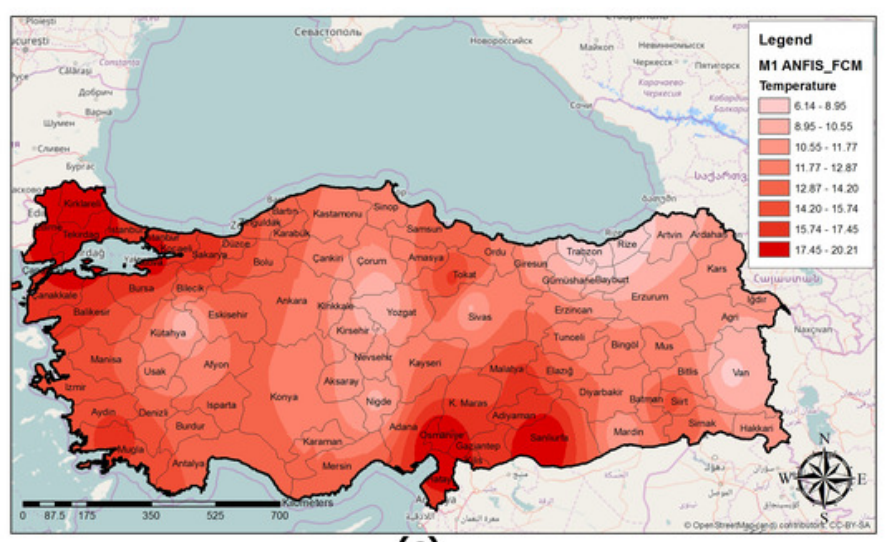

(c)
M1 ANFIS_GP

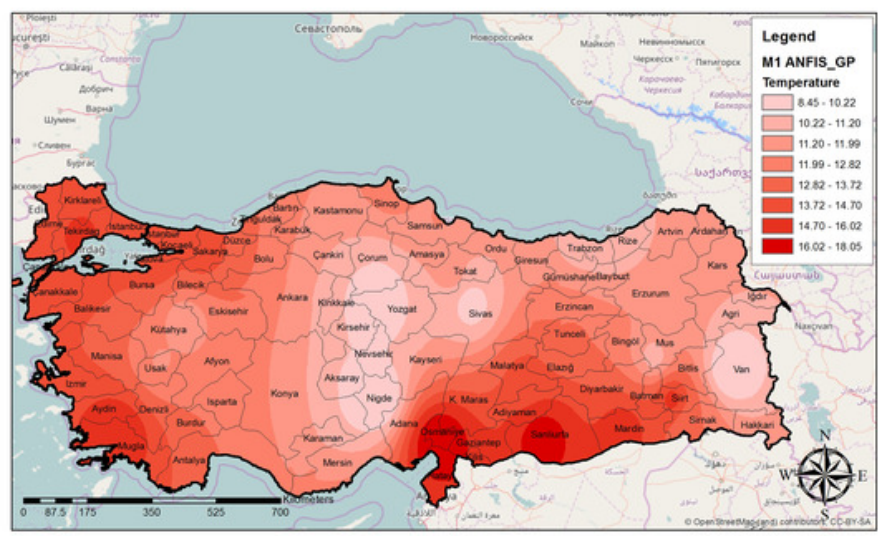

(b)

M1 FG_Fuzzy_G

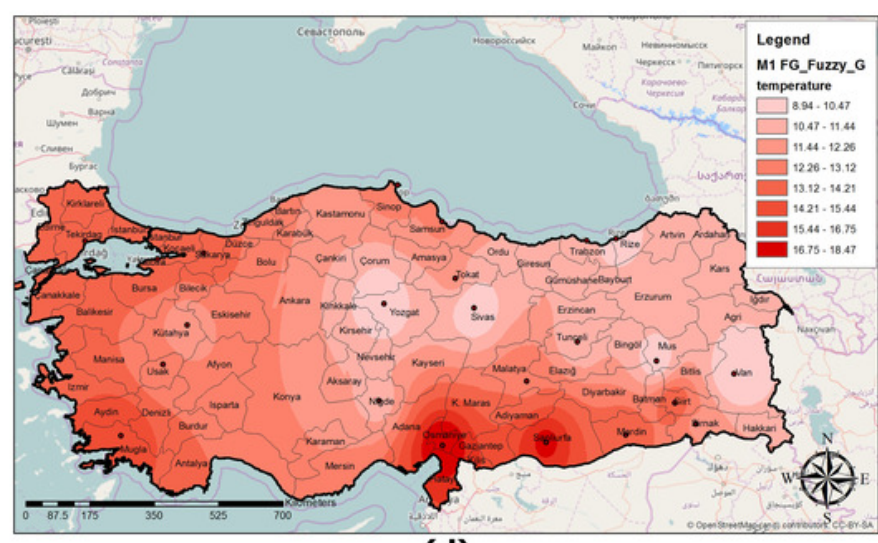

(d) 
Figure 9

Figure 9.

M2 model output maps for (a) ANFIS-SC, (b) ANFIS-GP, (c) ANFIS-FCM and (d) FG

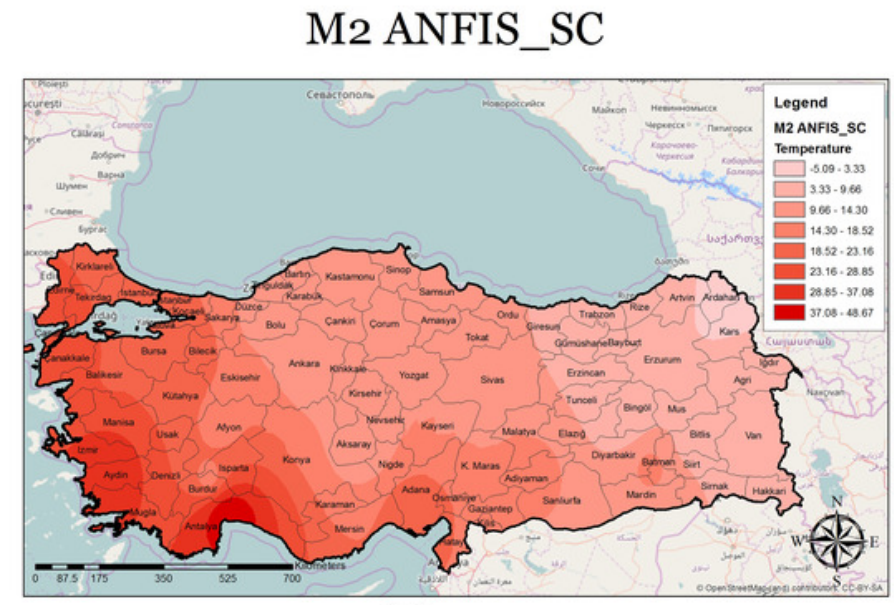

(a)

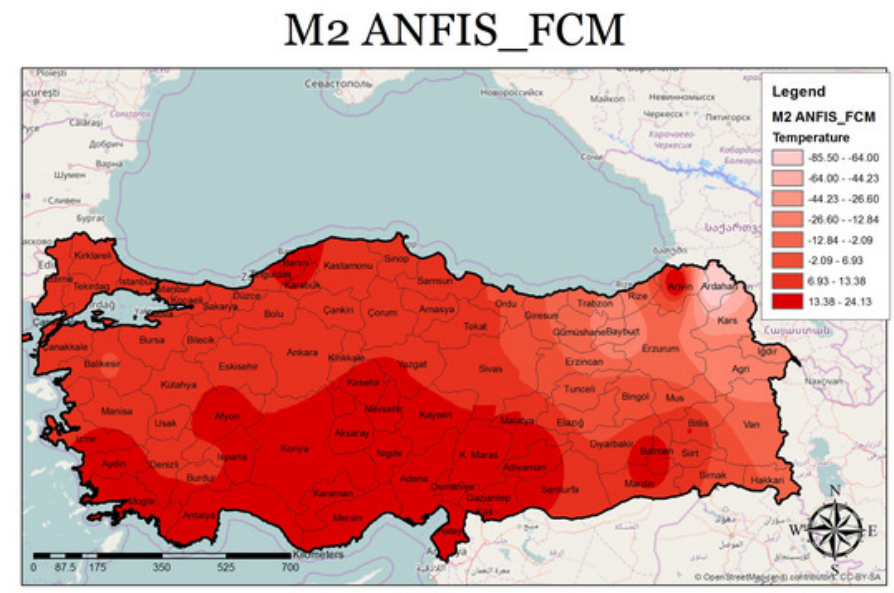

(c)

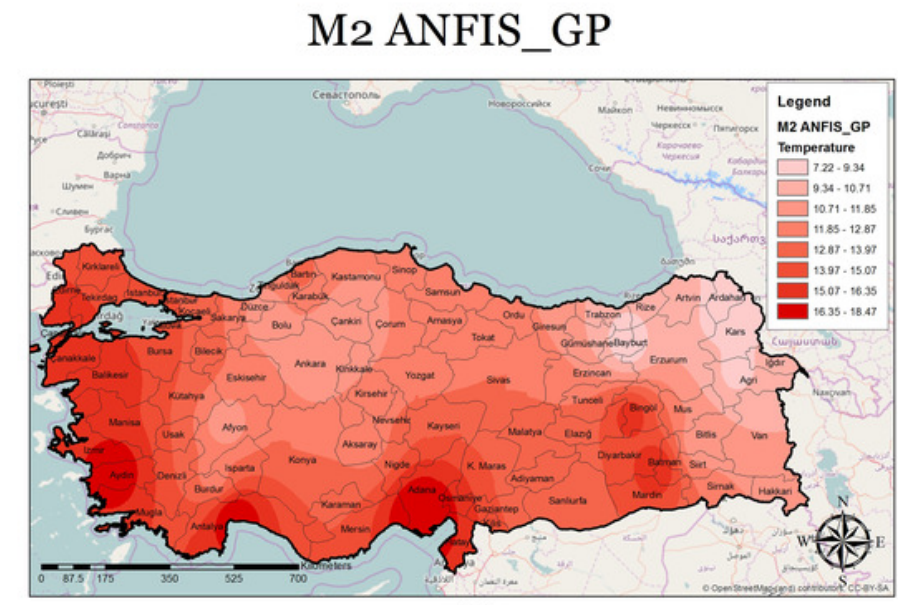

(b)

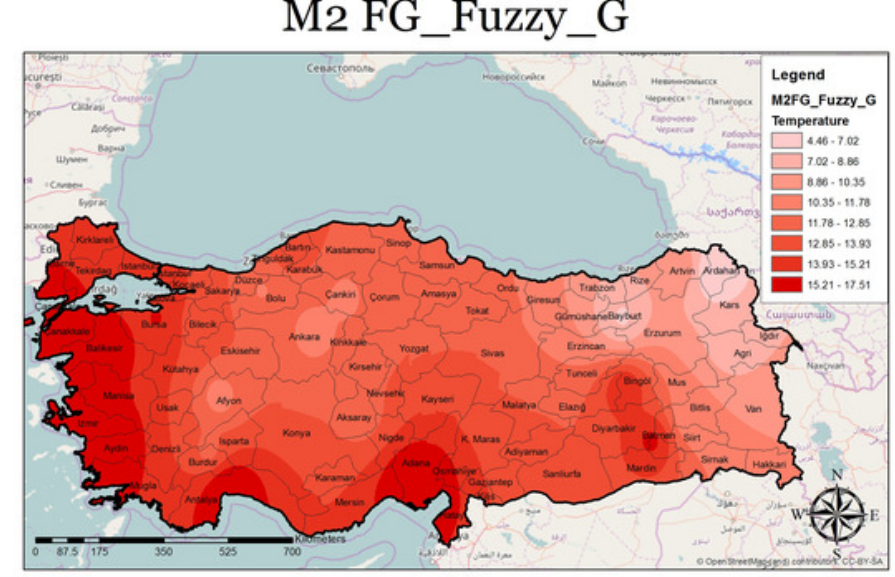

(d) 
Figure 10

Figure 10.

M3 model output maps for (a) ANFIS-SC, (b) ANFIS-GP, (c) ANFIS-FCM and (d) FG

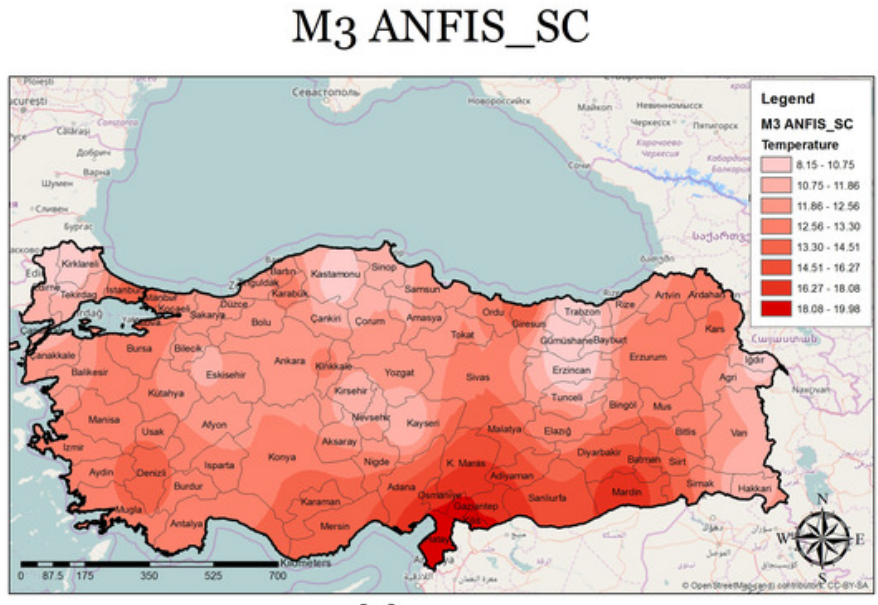

(a)

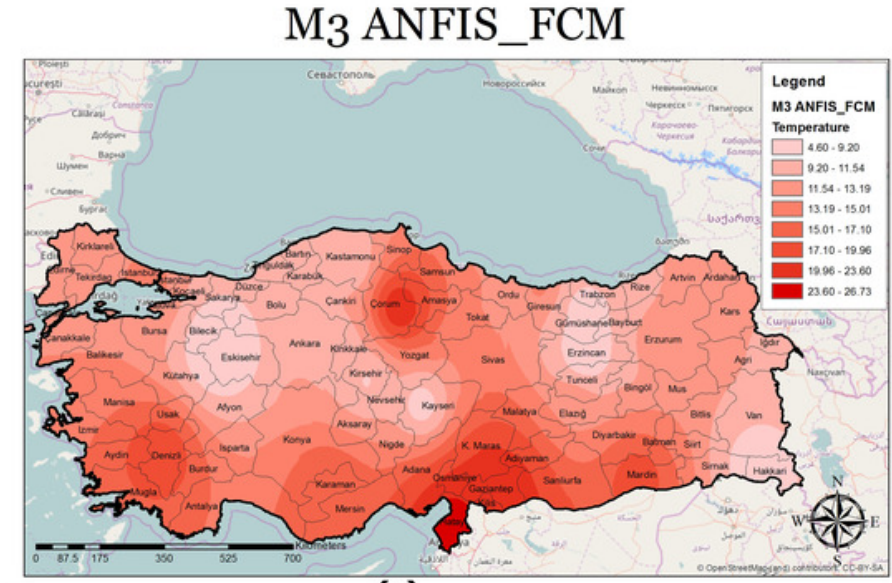

(c)

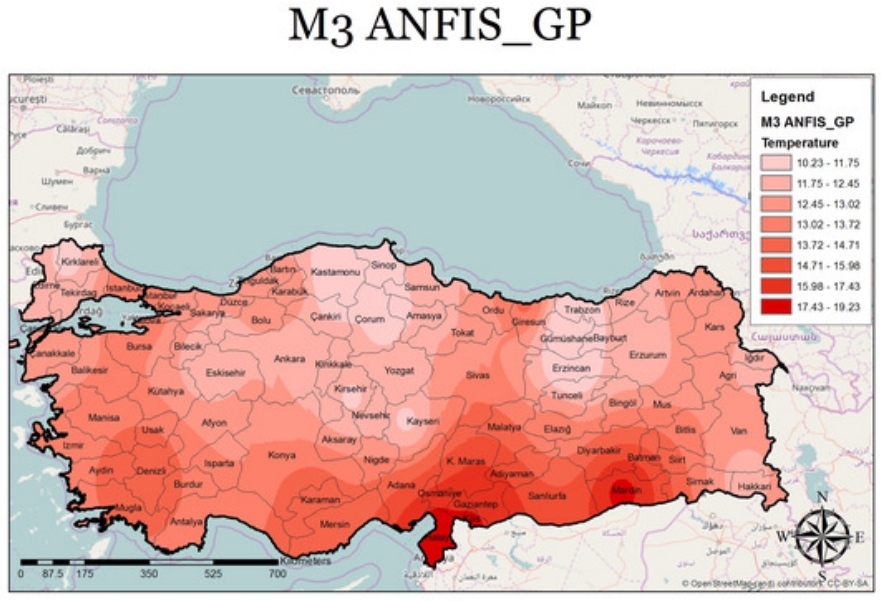

(b)

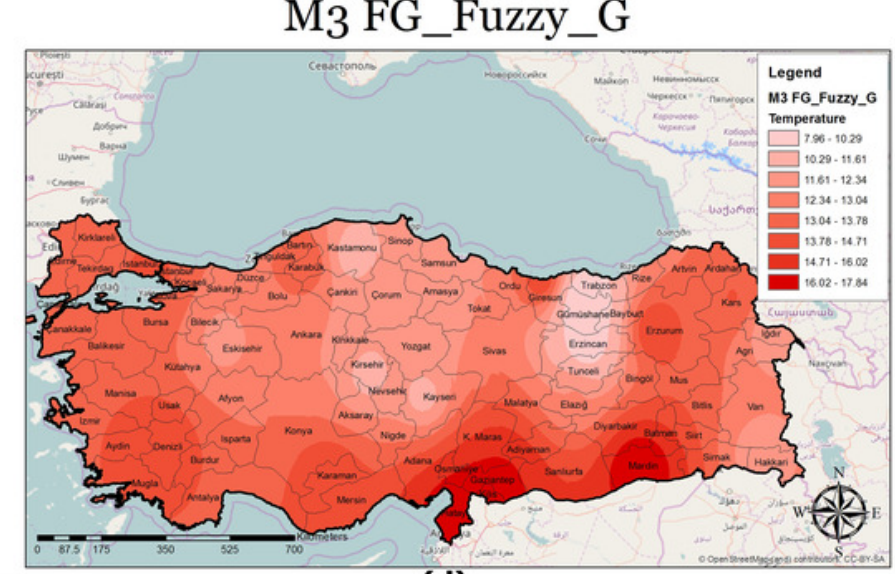

(d) 